\title{
MJN TRANSLATING HAND HYGIENE PRACTICE INTO COMPLIANCE DURING ASEPTIC WOUND DRESSING
}

\author{
Iszaid Bin Idris*, Azizan Binti Atan, Noor Shahidah Binti Ahmad Yatim, Mahani Binti Abdullah \\ Hospital Pontian, Johor, Malaysia \\ *Corresponding Author's Email: iszaid_bijaksana@yahoo.com.my
}

\begin{abstract}
Background: Over the past decade, we have witnessed some amazing innovations in the field of aseptic wound dressing. Unfortunately, many reports showed hand hygiene compliance remains poorly observed. In the late $1800 \mathrm{~s}$, Florence Nightingale had revolutionised our understanding by introducing the principle of hand washing and other hygienic practice during the Crimean War. Growing burden of healthcare-associated infection have yielded enough scientific evidence to support the claim that hand hygiene alone is capable of substantially reducing the risk of cross-transmission. The objective of this study is to explore factors associated with hand hygiene compliance during aseptic wound dressing among healthcare workers. Methods: This is a cross-sectional survey conducted among various public healthcare workers in the state of Johor (Malaysia). Descriptive and inferential statistics were computed to analyse the data. Results: A total of 451 Health Care Workers (HCW)s have volunteer and out of which majority work as a Registered Nurse $(n=262,58 \%)$, compared to other health workers $(n=189,42 \%)$. Almost all of HCWs $(n=446,99 \%)$ feel wound dressing took long time to finish regardless of experience. We found that using the standardised forms as the assisting method significantly improved hand hygiene compliance during aseptic wound dressing regardless of working experience. Conclusion: Although nurses are predominantly responsible for handling wound care, various other factors are accountable for the adherence towards hand hygiene practice.
\end{abstract}

Keywords: Translating Practice; Hand Hygiene Compliance; Wound Dressing

\section{INTRODUCTION}

Caring for people with wounds can be considered as a major health burden (Dabiri, Damstetter \& Phillips, 2014). Poor wound healing is often attributed to failure to comply with standard hygiene procedures (Hammerschmidt \& Manser, 2019). Over the past decade, we have witnessed some amazing innovations in the field of aseptic wound dressing. However, hygiene compliance during this common procedure still remains poorly observed (Zivich, Gancz \& Aiello, 2018). Addressing this concern is important not only for patient recovery but also for the credibility of treating clinician especially the nurses. Furthermore, the imperative role of hand hygiene is paramount important in almost every clinical practice. Consequent of wound related contamination in health facilities, particularly in the hospital environment, is not uncommon (Sergent et al., 2012). Eventually, suboptimal practice may invite microbial colonisation into the wound and the transmission of harmful pathogens such as Clostridium difficile, Acinetobacter spp., Vancomycin-Resistant
Enterococci (VRE), Norovirus and MethicillinResistant Staphylococcus aureus (MRSA) from patient to patient via the healthcare workers (Sergent et al., 2012).

The practice of dressing wounds dates back to as early 2200 B.C (Beers, 2019). At that time, the principle of wound dressing included washing the wound with beer then warm water, followed by covering the wound with a plaster mixture of oily herbs and the subsequent application of a bandage (Gibran \& Curtis, 2019). However, in the late 1800 s, Florence Nightingale, the woman who many cite as the founder of modern nursing and known as 'the lady with the lamp', revolutionised the practice by implementing the principle of hand washing and other hygienic practice during the Crimean War (Dumitrascu et al., 2020). Today, the hygiene principles Nightingale pioneered remain almost the same, with the wound dressing procedure is still predominantly performed by nurses (Guest et al., 2017). It is also assumed that wound healing has been under the aegis of basic nursing practice (Sen, 2019). In today 
standard, nurses will often spend an estimated $25-50 \%$ of their time dealing with various types of wounds, which typically range from acute wounds, such as simple lacerations, to more chronic wounds, such as bedsores or diabetic leg ulcers (Gillespie et al., 2020). Although nurses play a crucial role handling wound related procedure, it is not uncommon in today practice that other non-nurse Health Care Worker (HCW) getting involved in managing the wound care.

Growing burden of healthcare-associated infection have yielded enough scientific evidence to support the claim that hand hygiene alone is capable of substantially reducing the risk of cross-transmission during aseptic wound dressing (Allegranzi \& Pittet, 2009). In some study suggest, adherence to recommended hand washing practice has been found to be alarmingly low, as low as $40 \%$ (Mathur, 2011). In the UK alone, the government spends almost about $£ 5$ billion a year on managing more than an estimated 2.2 million wounds and their associated complications (Guest et al., 2017). In the global context, the cost is more substantial; some expert predicts wound care market could project to reach $£ 34$ billion equivalent to compound annual growth rate at $4.6 \%$ by 2024 (Sen, 2019).

To contribute in solving the problem described above, this study explores factors associated with hand hygiene compliance during aseptic wound dressing among healthcare workers. It does so with the aim of laying the foundation for improvements in health policy at all levels in health facilities.

\section{METHODOLOGY}

This is a cross-sectional survey conducted among volunteer from various public $\mathrm{HCW}$ in Johor State, Malaysia. They were randomly selected participants during the online training course at the Clinical Nursing Education Session on $30^{\mathrm{th}}$ November, 2020. The program had been conducted by Nursing Unit of Hospital Pontian in cooperation with Johor States Health Department. The survey material was developed after reviewing the current literature and had been validated by expert in the field. Inclusive criteria of this study include all healthcare worker involved in wound care procedure primarily still working in any of public health facilities such as the clinic, field-community, military health, training institute, dental and hospital settings. Exclusion criteria includes those participants who were less than $<6$ month of working duration at the Johor States Health Department. Questions were given to participants during the session after consented through restricted online platform of the Google form. Respondent details were then extracted by Software using restricted Google sheet pertaining to socio-demographic (such as age, type of job, education level, work setting, numbers of experience and numbers of procedure per month), wound dressing experience and association factor towards hand hygiene compliance (such as formal training, reporting method, working time and assisting method). Data from respondent was then stored by using Microsoft Excel version 2007, and then analysed by using Epi Infotm version 7. This study was registered with National Medical Research Register NMRR ID-21-01956-WJV and obtained appropriate approval from Hospital Pontian Ethical Committee Dated on $29^{\text {th }}$ November 2020.

\section{RESULTS \& DISCUSSION}

A total of $451 \mathrm{HCWs}$ have volunteer and out of which majority work as a Registered Nurse $(\mathrm{n}=262,58 \%)$, compared to other health workers $(\mathrm{n}=189,42 \%)$. Figure 1 showed the proportion of $\mathrm{HCW}$ involved in wound dressing at the government health facilities in Johor, Malaysia. We found that average respondents age involved in wound care were $33.0 \pm 4.9$ SD (StandardDeviation) years old. More than half of HCWs have at least Diploma $(\mathrm{n}=274,61 \%)$, followed by Degree $(\mathrm{n}=106,24 \%)$, Master $(\mathrm{n}=5,1 \%)$ and other level of education $(\mathrm{n}=66,15 \%)$. The study showed most of the HCWs are working at the Hospital $(\mathrm{n}=206,46 \%)$, followed by clinic $(n=136,30 \%)$, dental office $(n=77$, $17 \%)$, teaching institution $(\mathrm{n}=18,4 \%)$ and other health facilities $(\mathrm{n}=11,3 \%)$. We also found that majority of $\mathrm{HCW}$ s were well experienced in wound care management of $>6$ years $(\mathrm{n}=227,50 \%)$, followed by $1-3$ years $(n=104,23 \%), 4-6$ years $(n=76,17 \%)$, and 6 month-1 year $(n=42,10 \%)$. The average number of wound care procedure performs by the HCWs were $6.7 \pm$ 9.1 SD procedures per month for each individual.

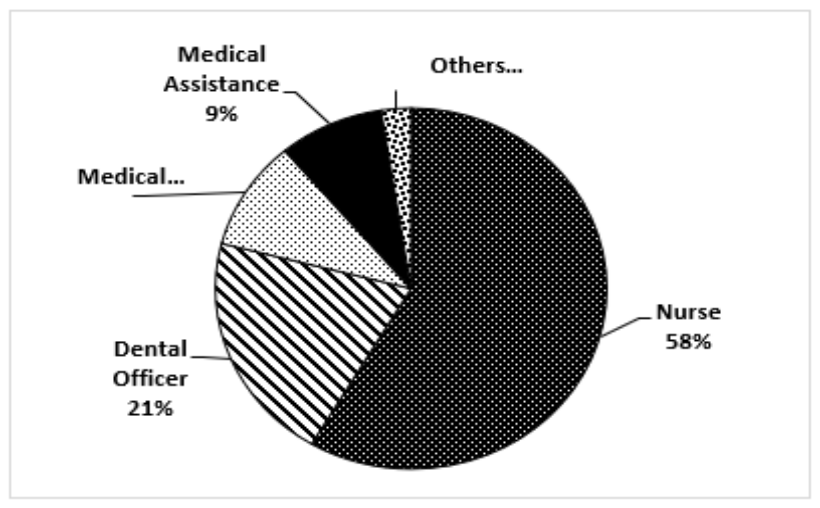

Figure 1: Proportion of Healthcare Worker (HCW) Involved in Wound Dressing 
The survey also looked into wound dressing experience in daily basis. Based on Figure 2, it showed almost all of HCWs ( $\mathrm{n}=446,99 \%)$ feel wound dressing took long time to finish regardless of experience. Furthermore, majority of HCWs ( $\mathrm{n}=313,97 \%)$ agree that hand hygiene have some value in wound dressing outcomes. Interestingly, large parts of HCWs feel that there is some value for assisted tools or method to improve hand hygiene compliance.

Using the questionnaire as a guided for developing variables, we found that work experience as cofounder among hand hygiene compliance. Table 1 showed adjusted odd ratios obtained from multivariate conditional logistic regression between factors associated aseptic wound dressing procedure and awareness on hand hygiene that had been adjusted by work experience. From this model we can predict that by implementing an assisting method for wound dressing procedure can significantly increase compliance on hand hygiene during aseptic wound dressing procedure.

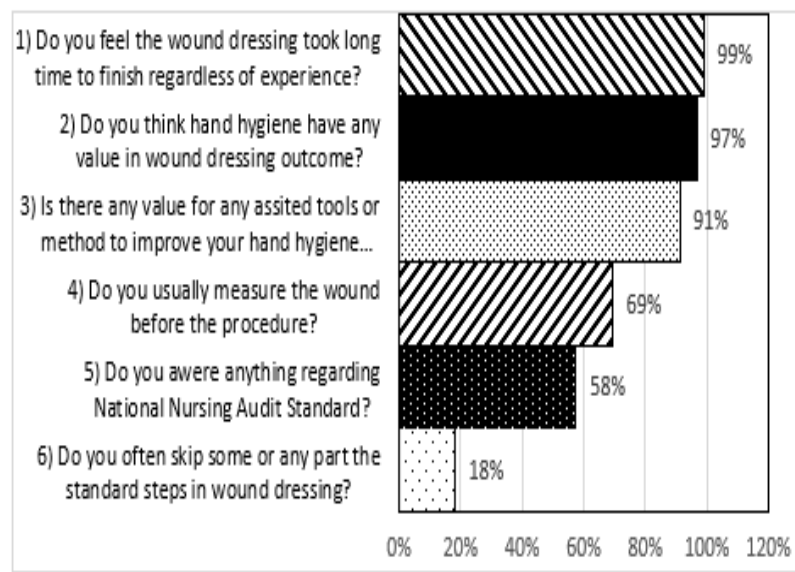

Figure 2: Survey on Hand Hygiene Compliance During Aseptic Wound Dressing Procedure

Table 1: Multivariate Conditional Logistic Regression between Factors Associated Aseptic Wound Dressing Procedure and Compliance on Hand Hygiene Being Adjusted by HCWWork Experience

\begin{tabular}{|c|c|c|c|c|c|c|}
\hline Variable & $\begin{array}{l}\text { Compliance to } \\
\text { Hand Hygiene, } \\
\text { n }(\%)\end{array}$ & $\begin{array}{l}\text { Not } \\
\text { Compliance to } \\
\text { Hand Hygiene, } \\
\text { n (\%) }\end{array}$ & $\begin{array}{l}\text { Crude OR } \\
(95 \% \text { CI) }\end{array}$ & $p$ & $\begin{array}{l}\text { Adjusted OR } \\
(95 \% \text { CI })\end{array}$ & $p$ \\
\hline \multicolumn{7}{|l|}{ Formal Training } \\
\hline Fully attended & $76(42)$ & $98(37)$ & $1.2(0.9-1.9)$ & 0.066 & - & - \\
\hline Never or incomplete & $104(58)$ & $169(63)$ & & & & \\
\hline \multicolumn{7}{|l|}{ Reporting Method } \\
\hline Medical notes & $144(55)$ & $154(86)$ & $4.9(3.0-7.9)$ & $<0.001$ & $5.2(3.1-8.6)$ & 0.971 \\
\hline No report at all & $119(45)$ & $26(14)$ & & & & \\
\hline \multicolumn{7}{|l|}{ Working Time } \\
\hline Shift / Flexy hours & $92(51)$ & $30(11)$ & $8.3(5.1-13.4)$ & $<0.001$ & $7.1(4.3-11.8)$ & 0.591 \\
\hline Office hours & $88(49)$ & $238(89)$ & & & & \\
\hline \multicolumn{7}{|l|}{ Assisting Method } \\
\hline Standardized Form & $136(77)$ & $36(14)$ & $21.1(12.9-34.6)$ & $<0.001$ & $17.5(10.6-28.9)$ & $0.031 *$ \\
\hline No assisted method & $41(23)$ & $229(86)$ & & & & \\
\hline
\end{tabular}

OR: Odd Ratios, CI: Confidence Interval, $p$ : P-Values, *Significant at $p<0.05$

In general, the study explores hand hygiene compliance during the aseptic wound dressing procedure. From the data gathered from various public health facilities in Johor, Malaysia, we found that using the standardised forms as the assisting method significantly improved hand hygiene compliance during aseptic wound dressing regardless of working experience. Although other factors can potentially improve hand hygiene compliance, our study shows that formal training alone is insufficient to improve the outcome of $\mathrm{HCW}$ including the nurses.

A close examination of the data reveals that nurses are predominantly responsible for wound dressing (Guest et 
al., 2017). In addition, we found that most HCWs have more than six years' experience in carrying out the wound dressing procedure since they are typically older than 30 years of age. Contrastingly, this finding does not support other studies which state that the greater the age of HCWs, the more likely they are to be involved in wound dressing (Gillespie et al., 2020). Thus, we posit that wound dressing responsibilities have no correlation with HCW's experience. In addition, HCWs were found to be predominantly educated to diploma-level, which may be explained by the minimal educational requirement to become a registered nurse in their local setting. Our study also shows that large portion of HCWs involved in wound dressing work in public hospitals. This is to be expected due to the large portion of HCWs employed in hospitals compared to other health facilities. On average, an HCW will dedicate approximately $35-40 \%$ of their working time to managing wounds, carrying out an average of 6.7 procedures per month. This study also highlights that most HCWs will skip the steps in the wound dressing procedure as a time-saving measure. In general, we found considerable variation in hand hygiene compliance toward wound care regardless of work-related factors. This finding is similar to other more comprehensive study pertaining to hand hygiene compliance (Gould et al., 2017). Moreover, this study is able to explore various possible factors associated with hand hygiene compliance during aseptic wound dressing which can be the cornerstone for health-related policy maker.

Indeed, sometimes staying current is not easy. Apart from doing a small research study, involving in quality assurance project and encourage creative way to educate the HCWs especially the nurses are the way forwards. The use of information technology to facilitate any wound related procedure could potentially improve the hand hygiene compliances. The readiness of nurses to takes up such innovative challenges should be acknowledged. Last year, a group of nurses at District Hospital Pontian (without specialist) come out with genius innovation to improve their daily workflow in managing aseptic wound dressing, saving time with help of technology.

We believe that the right method of wound dressing is essential to speed up the healing process at the same time prevent complication. In many parts of the world, wound care involves multidiscipline and sometimes multiple staff such as nurses and other paramedics (Gould et al., 2017). Hence, standard procedure should be introduced and implemented across the nation. In Malaysia for example, the National Wound Care Committee published a specific clinical practice guidelines in managing wound care published in the year 2014 (Ministry of Health Malaysia, 2014). It provides various practice aspects in wound care. It is also important that policy should be regularly updated and written in the native language to diversify the audience across various parts of health care.

The study has several limitations such as the study period is too shorts due to COVID-19 pandemic which inhibit dissemination of physical outreach and movement control order being implemented nationwide. Secondly, the targeted HCWs only cover public facilities which may or may not be applicable to private health institution. Hence, future study should take into consideration wider time frame and population.

\section{CONCLUSION}

The study findings highlight the need for more tools to improve hand hygiene compliance during aseptic wound dressing as a means of ensuring standard procedures are followed, and wounds are properly cared for. Although nurses are predominantly responsible for handling wound care, but various factors are almost similar which can improve adherence to hand hygiene standards, and experience can be gained along the way.

\section{Recommendation}

Gauging attitudes towards standard procedure in hand hygiene tend to be neglected in clinical research. A standard procedure remains heavily dependent on the attitude of HCWs themselves. The practice of sharing lessons learned through experience will potentially lead to reflective practice and improved knowledge, encouraging HCWs to adhere to infection control protocol in order to improve wound care and prevent cross-contamination. In addition, this will provide the basis for health policymakers to prioritise training, research and indirectly workforce in the field of infection control nursing in public healthcare facilities. As a result, HCWs will become more aware of the importance of following hygiene protocol and subsequently work to become more efficient during the aseptic wound dressing procedure.

\section{Conflict of Interests}

The authors declare that they have no conflict of interests.

\section{ACKNOWLEDGEMENT}

The authors would like to thank the Director General of Health Malaysia and Director of Johor State Health 
Department for their permissions to publish this article. Neither funding nor conflict of interest was applicable.

\section{REFERENCES}

Allegranzi, B., \& Pittet, D. (2009). Role of hand hygiene in healthcare-associated infection prevention. Journal of Hospital Infection, 73(4), 305-315.

Beers, E. H. (2019). Palliative wound care: less is more. Surgical Clinics, 99(5), 899-919.

Dabiri, G., Damstetter, E., \& Phillips, T. (2014). Choosing a Wound Dressing Based on Common Wound Characteristics. Advances in Wound Care, 5(1), 32-41.

Dumitrascu, D.I., David, L., Dumitrascu, D.L., \& Rogozea, L. (2020). Florence Nightingale bicentennial: 1820-2020. Her contributions to health care improvement. Medicine and Pharmacy Reports, 93(4), 428.

Gibran, N.S., \& Curtis, E. (2019). History of Wound Care. In J. Marc G., K. Lars-Peter, \& S. Folke (Eds.), Handbook of Burns ( $2^{\text {nd }}$ ed., vol. 1, pp. 423-430). Springer Nature.

Gillespie, B.M., Walker, R., Lin, F., Roberts, S., Eskes, A., Perry, J., Birgan, S., Nieuwenhoven, P., Garrahy, E., \& Probert, R. (2020). Wound care practices across two acute care settings: A comparative study. Journal of Clinical Nursing, 29(5-6), 831-839.

Gould, D.J., Moralejo, D., Drey, N., Chudleigh, J.H., and Taljaard, M. (2017). Interventions to improve hand hygiene compliance in patient care. Cochrane Database of Systematic Reviews, 8(9).

Guest, J.F., Ayoub, N., McIlwraith, T., Uchegbu, I., Gerrish, A., Weidlich, D., Vowden, K., \& Vowden, P. (2017). Health economic burden that different wound types impose on the UK's National Health Service. International Wound Journal, 14(2), 322-330.

Hammerschmidt, J., \& Manser, T. (2019). Nurses' knowledge, behaviour and compliance concerning hand hygiene in nursing homes: a cross-sectional mixed-methods study. BMC Health Services Research, 19(1), 1-13.

Mathur, P. (2011). Hand hygiene: Back to the basics of infection control. In Indian Journal of Medical Research (vol. 134, issue 11, pp. 611-620). Medknow Publications \& Media Pvt Ltd.

Ministry of Health Malaysia. (2014). Wound Care Manual. https://www.moh.gov.my/moh/resources/Penerbitan/Garis Panduan/Garis Panduan Umum(KKM)/Wound_Care_Manual.pdf

Sen, C.K. (2019). Human Wounds and Its Burden: An Updated Compendium of Estimates. Advances in Wound Care, $8(2), 39-48$.

Sergent, A., Slekovec, C., Pauchot, J., Jeunet, L., Bertrand, X., Hocquet, D., Pazart, L., \& Talon, D. (2012). Bacterial contamination of the hospital environment during wound dressing change. Orthopaedics \& Traumatology: Surgery \& Research, 98(4), 441-445.

Zivich, P.N., Gancz, A.S., and Aiello, A.E. (2018). Effect of hand hygiene on infectious diseases in the office workplace: A systematic review. American Journal of Infection Control, 46(4), 448-455. 